\begin{tabular}{ll|l} 
Case Reports in & \multicolumn{2}{c}{ Case Rep Gastroenterol 2013;7:381-387 } \\
\cline { 2 - 3 } Gastroenterology & $\begin{array}{l}\text { DOI: 10.1159/000355155 } \\
\text { Published online: September 5, 2013 }\end{array}$ & $\begin{array}{l}\text { ○ 2013 S. Karger AG, Basel } \\
\text { www.karger.com/crg }\end{array}$ \\
\hline & $\begin{array}{l}\text { This is an Open Access article licensed under the terms of the Creative Commons } \\
\text { Attribution-NonCommercial 3.0 Unported license (CC BY-NC) (www.karger.com/OA- } \\
\text { license), applicable to the online version of the article only. Distribution permitted for non- } \\
\text { commercial purposes only. }\end{array}$
\end{tabular}

\title{
Adult Colocolic Intussusception and Literature Review
}

\author{
Abralena Wilson George Elias Rulx Dupiton \\ Lincoln Medical and Mental Health Center, Fort Lee, N.J., USA
}

\section{Key Words}

Adult colocolic intussusception · Literature review · Adult · Intussusception · Colon .

Adenocarcinoma $\cdot$ Computed tomography scanning

\begin{abstract}
Intussusception occurs when a proximal segment of the gastrointestinal tract, called intussusceptum, telescopes into the lumen of an adjacent segment, also known as intussuscipiens. Although common in early childhood, intussusceptions are very rare in the adult population. Most intussusceptions in adults are due to a lead point, which is an identifiable pathological abnormality, in opposition to children which there are no identifiable pathological lead points. In contrast to childhood intussusception, in adults it is associated with malignant lesions, particularly in the large bowel rather than in the small bowel. Its preoperative diagnosis and treatment in adults is difficult because of nonspecific abdominal symptom and because it rarely presents with the classic triad of vomiting, abdominal pain and passage of blood per rectum. We present a 63-year-old female with an adenocarcinoma tumor being the lead point in a colocolic intussusception, who was diagnosed preoperatively with computed tomography and had a colonoscopy to rule out obstruction. She underwent right hemicolectomy with side-to-side ileocolic anastomosis and did well postoperatively. In addition, we also review the literature and discuss the value of radiological modalities, location and surgical management to try to improve the preoperative diagnosis. Computed tomography scanning with intravenous contrast is maybe the most accurate modality for diagnosis of intussusceptions in adults, and treatment is usually surgical resection without reduction, since most of the colonic lesions are malignant.

(c) 2013 S. Karger AG, Basel
\end{abstract}

Abralena J. Wilson

Lincoln Medical and Mental Health Center

132 Myrtle Ave Apt. 21

Fort Lee, NJ 07024 (USA)

E-Mail aby151@hotmail.com 
Wilson et al.: Adult Colocolic Intussusception and Literature Review

\section{Introduction}

Adult intussusception is rare, representing only $1-5 \%$ and $5 \%$ of all bowel obstructions and intussusceptions, respectively. A definable lead point is common in $70-90 \%$ of adult intussusceptions, as opposed to pediatric intussusception, which is idiopathic in $90 \%$ of cases [1-3]. The exact pathophysiology is not known. However, a plausible explanation is that if a lesion is present within the lumen, with the presence of food and peristaltic activity there is a narrowing above the stimulus and relaxation below, thus making the lead point (intussusceptum) telescope to the distal bowel [1, 4].

Pediatric intussusception most frequently presents with intermittent colicky pain, abdominal mass and passage of dark clots mixed with mucus [5]. In adults however, intussusception presents with acute, subacute or chronic nonspecific symptoms [5, 6]. Therefore, the diagnosis is usually missed or made with a delay in the operating room. Most adult intussusceptions require surgical intervention with resection due to intraluminal lesions. However, there is controversy on the amount to be resected and on whether intestinal intussusceptions should be reduced, since there is a significant $65 \%$ risk of malignancy regardless of anatomic site $[2,6,7]$. Thus, the diagnosis and therapeutic planning of intestinal tumors causing intussusception in adults has recently been made more feasible with the advent and accessibility of the imaging modality of multislice computed tomography (CT). We report a rare case of colonic adenocarcinoma presenting with intussusception diagnosed by CT scan and confirmed by immunohistochemistry, and present a brief review of the literature.

\section{Case Report}

A 63-year-old Caucasian female with no significant past medical history presented with a 1-month history of intermittent right upper quadrant pain radiating to the umbilicus after $1 \mathrm{~h}$ of eating food. She also had decreased appetite, with an unintentional weight loss of 20 lbs within the past 6 months. In addition, she had had 1 year of nonbloody diarrhea with no history of travelling. She denied any chills, fevers, nausea or vomiting. Her surgical history included appendectomy, with no family history of colon cancer but significant for Crohn's disease.

At the time of presentation to the emergency room, her temperature was $98.1^{\circ} \mathrm{F}$, blood pressure $175 / 83 \mathrm{~mm} \mathrm{Hg}$, pulse 76 beats per minute, respiratory rate 16 breaths per minute and oxygen saturation $99 \%$ while breathing ambient air. At abdominal examination she had appreciable bowel sounds with a right lower mild tender and palpable abdominal mass but no rebound tenderness. Laboratory test were within the normal range: blood cell count $8,800 / \mu \mathrm{l}$, hemoglobin $9.5 \mathrm{~g} / \mathrm{dl}$ and hematocrit $40.6 \% \mathrm{~g} / \mathrm{dl}$. However, she had an elevated CEA level of $78 \mu \mathrm{g} / \mathrm{l}$ with abdominal CT scan that showed considerable edema of the intussusception of the proximal colon into the mid-transverse colon, due to a tumor measuring $4.1 \times 6.3 \mathrm{~cm}$, with no obstruction. The small bowel loops were normal in caliber, but there was significant edema from the distal transverse colon almost to the splenic flexure (fig. 1). Colonoscopy was performed to further evaluate the lead point of the intussusception, which was a tumor located at $65 \mathrm{~cm}$ in the transverse colon, causing partial obstruction. A biopsy was obtained at $60 \mathrm{~cm}$, which showed colonic mucosa with focal erosion, congestion and focal hyperplastic changes.

Based on these findings we diagnosed the patient with colocolic intussusception caused by colonic tumor. We performed an exploratory laparotomy that revealed an ascending $4.7 \times$ 
Wilson et al.: Adult Colocolic Intussusception and Literature Review

$3.5 \times 2.0 \mathrm{~cm}$ tumor as the lead point of intussusception into the proximal transverse colon, with palpable mesentery lymph nodes and no liver lesions (fig. 2). The patient underwent right hemicolectomy with side-to-side ileocolic anastomosis. The postoperative course was uneventful, and she was discharged home after 6 days in good general condition. Histopathological examination of the tumor revealed high-grade mucinous adenocarcinoma with signet ring cells with 12 out of 12 lymph nodes negative for metastasis (fig. 3). The final pathology staging was T3N0M0 or stage II.

\section{Discussion}

Intussusception is a very uncommon cause of intestinal obstruction in adults. Most lead points in the small bowel are benign lesions compared to the large bowel, 66 and 30\%, respectively $[2,6,7]$. The most common malignant tumors in the colon are usually adenocarcinomas. Since it is evident that $64 \%$ of colocolic intussusceptions are malignant adenocarcinomas as seen in the meta-analysis of several retrospective studies $[5,6,8]$, the $64 \%$ frequency of malignant tumors from our meta-analysis is within the frequency of malignant tumors seen in other studies (69-100\%) $[2,6,9]$.

With regards to symptoms, our patient presented with chronic abdominal pain, which is the most common clinical feature of all adult intussusception cases, as seen in the literature $[2,6,7]$. In contrast, the least common presenting sign at physical examination in the literature was palpable abdominal mass $[2,6,7]$. According to one retrospective study, a palpable abdominal mass was appreciated $62.3 \%$ of the time $(n=16)$, whereas other studies have indicated abdominal mass findings in between 24 and $42 \%$ [10, 11]. Other complaints include nausea and vomiting (36-82\%), diarrhea, bleeding or melena (18-29\%) and constipation (4-29\%) [4, 8, 12-14].

Although diagnostic workup with abdominal X-rays may show signs of intestinal obstruction, the most sensitive study to diagnose intussusceptions is abdominal CT, which provides a diagnostic accuracy of $83 \%$, made evident in the meta-analysis of recent studies $[5,6,8]$. One of the characteristic features described on CT scan is the presence of a targetor sausage-shaped lesion [15]. CT has therefore become the preferred imaging study compared to colonoscopy, ultrasonography and small bowel series.

\section{Conclusions}

Colonoscopy may be a useful tool for evaluating intussusception, in particularly when symptoms of large bowel obstruction are present [5]. We performed colonoscopy in our patient in order to evaluate bowel obstruction. However, surgery is the treatment of choice for colonic obstructing lesions and is usually done emergently. Colonoscopy should be performed when there is concern of obstructing signs and symptoms or to identify the location of the lesion as a preoperative workup, in the intent for surgical intervention as in the case illustrated above. The diagnostic value of CT scan is invaluable in adult colocolic intussusceptions. In addition, there are advantages in using colonoscopy in further assessing obstructive bowel lesions and evaluating whether there are any synchronous lesions that may be malignant and not seen on CT scan. Since there is a $64 \%$ higher risk of associated malignancy with adult intussusceptions, regardless of anatomic site, endoscopic reduction should only be considered if a benign lesion has been identified by colonoscopy. Therefore, future research will be needed to determine a standard treatment of adult intussusceptions and 
Wilson et al.: Adult Colocolic Intussusception and Literature Review

emphasizing the need of en bloc resection for colocolic intussusceptions due to the higher risk of malignancy.

\section{References}

1 Azar T, Berger DL: Adult intussusception. Ann Surg 1997;226:134-138.

-2 Begos DG, Sandor A, Modlin IM: The diagnosis and management of adult intussusception. Am J Surg 1997;17:88-94.

-3 Weilaecher D, Bolin JA, Hearn D, Ogden W 2nd: Intussusception in adults. Review of 160 cases. Am J Surg 1971;121:531-535.

-4 Nagorney DM, Sarr MG, McIlrath DC: Surgical management of intussusception in the adult. Ann Surg 1981;193:230-236.

5 Yakan S, Caliskan C, Makay O, Denecli AG, Korkut MA: Intussusception in adults: clinical characteristics, diagnosis and operative strategies. World J Gastroenterol 2009;15:1985-1989.

-6 Wang LT, Wu CC, Yu JC, Hsiao CW, Hsu CC, Jao SW: Clinical entity and treatment strategies for adult intussusceptions: 20 years' experience. Dis Colon Rectum 2007;50:1941-1949.

7 Eisen LK, Cunningham JD, Aufses AH Jr: Intussusception in adults: institutional review. J Am Coll Surg 1999;188:390-395.

D8 Wang N, Cui XY, Liu Y, Long J, Xu YH, Guo RX, Guo KJ: Adult intussusception: a retrospective review of 41 cases. World J Gastroenterol 2009;14:3303-3308.

$\checkmark 9$ Reijnen H, Joossten H, de Boer H: Diagnosis and treatment of adult intussusception. Am J Surg 1989;158: 25-28.

10 Gupta RK, Agrawal CS, Yadav R, Bajracharya A, Sah PL: Intussusception in adults: institutional review. Int J Surg 2011;9:91-95.

11 Hanan B, Diniz TR, da Luz MM, da Conceição SA, da Silva RG, Lacerda-Filho A: Intussusception in adults: a retrospective study. Colorectal Dis 2010;12:574-578.

12 Goh BKP, Quah HM, Chow PKH, Tan KY, Tay KH, Eu KW, Ooi LL, Wong WK: Predictive factors of malignancy in adults with intussusception. World J Surg 2006;30:1300-1304.

13 Toso C, Erne M, Lenzlinger PM, Schmid JF, Buchel H, Melcher G, Morel P: Intussusception as a cause of bowel obstruction in adults. Swiss Med Wkly 2005;135:87-90.

14 Stubendbord WT, Thorbjarnarson B: Intussusception in adults. Ann Surg 1970;172:306-310.

15 Gayer G, Apter S, Hofmann C, Nass S, Amitai M, Zissin R, Hertz M: Intussusception in adults: CT diagnosis. Clin Radiol 1998;53:53-57. 

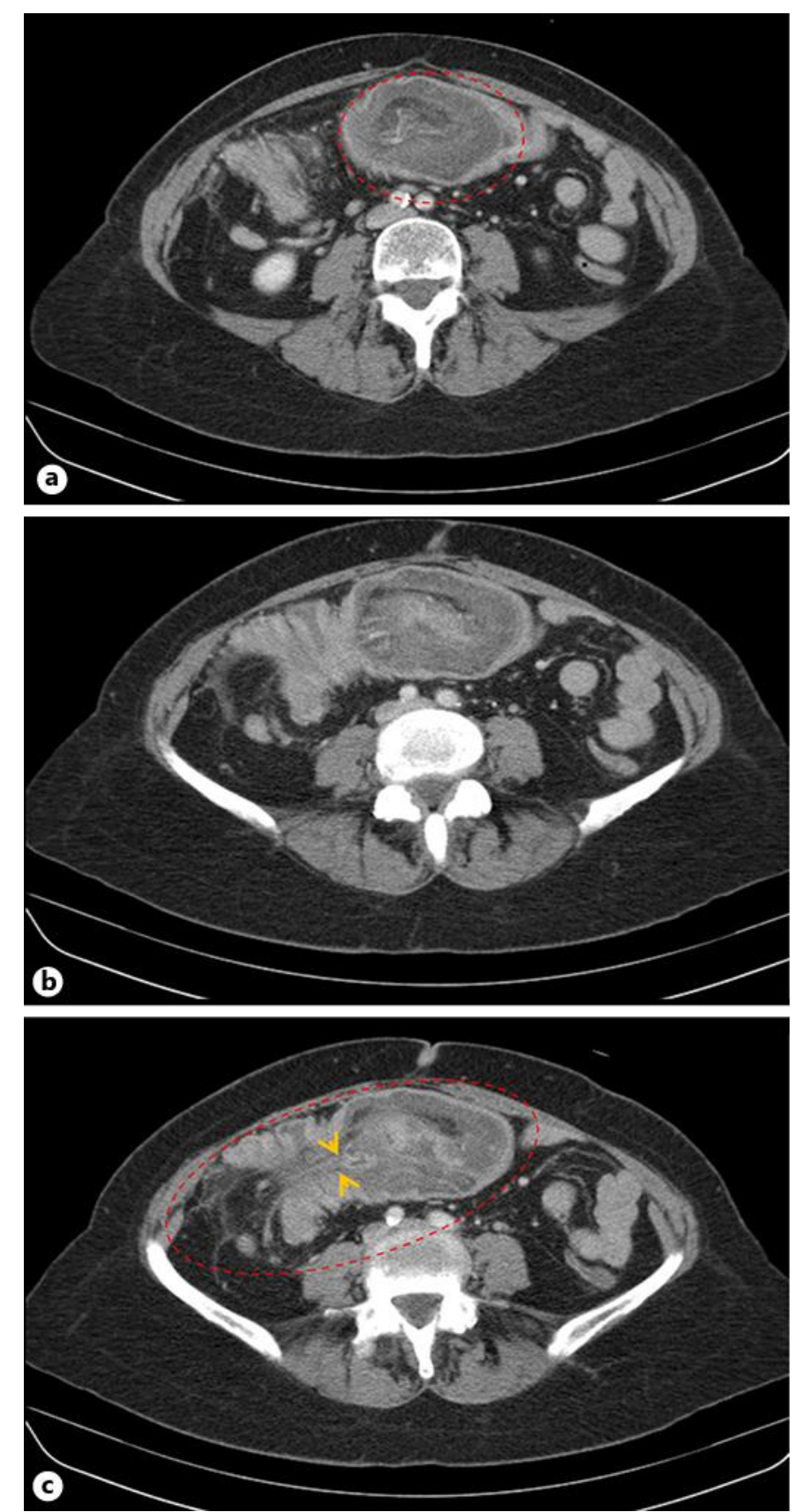

Fig. 1. Abdominal CT scan showing a heterogeneous soft tissue mass. a The 'target sign' seen with intussusceptions, which is then observed as the 'sausage sign' (b, c), as noted within the circular marking. There is radiolucent (dark) streak of fatty mesentery bordered by a sheath of hyperdense soft tissue of the bowel wall, as shown between the yellow arrowheads. 
Wilson et al.: Adult Colocolic Intussusception and Literature Review

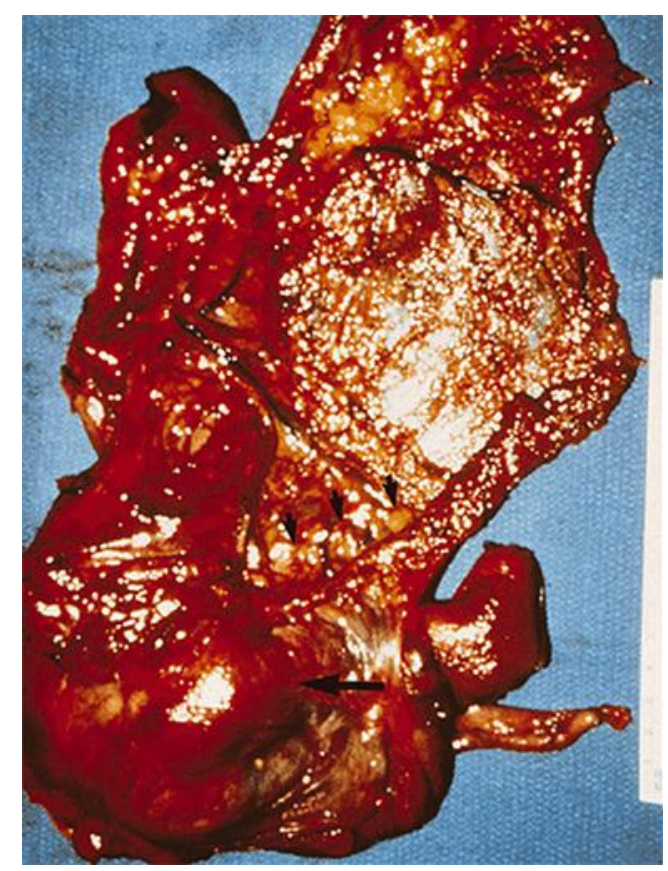

Fig. 2. Gross specimen of the ascending colon with the large arrow showing the tumor and the smaller arrows showing the palpable lymph nodes located in the mesentery. 


\begin{tabular}{|c|c|c|}
\hline \multirow{2}{*}{$\begin{array}{r}\text { Case Reports in } \\
\text { Gastroenterology }\end{array}$} & \multicolumn{2}{|c|}{ Case Rep Gastroenterol 2013;7:381-387 } \\
\hline & DOI: $10.1159 / 000355155$ & $\begin{array}{l}\text { (c) } 2013 \text { S. Karger AG, Basel } \\
\text { www.karger.com/crg }\end{array}$ \\
\hline
\end{tabular}

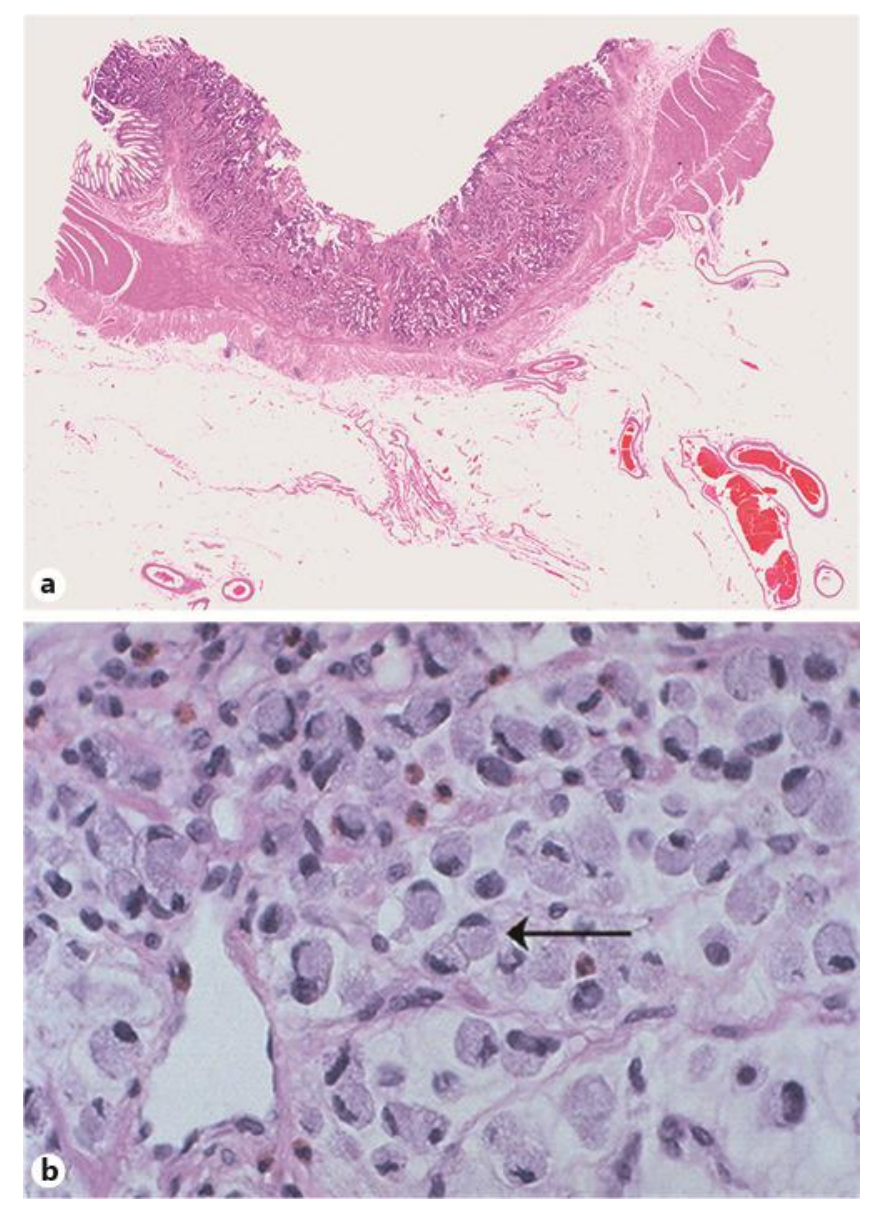

Fig. 3. a H\&E stain of the colon mass revealing invasion into the serosa. Original magnification $\times 40$. $\mathbf{b} \mathrm{H} \& \mathrm{E}$ stain of the colon segment demonstrating adenocarcinoma with presence of signet cells, as noted by the arrow. Original magnification $\times 400$. 